\title{
Prevalence of methicillin-resistant Staphylococcus aureus (MRSA) infection and the molecular characteristics of MRSA bacteraemia over a two-year period in a tertiary teaching hospital in Malaysia
}

\author{
Pik San Sit ${ }^{1}$, Cindy Shuan Ju Teh', Nuryana Idris ${ }^{1}$, I-Ching Sam', Sharifah Faridah Syed Omar ${ }^{2}$, Helmi Sulaiman²,
} Kwai Lin Thong ${ }^{3}$, Adeeba Kamarulzaman ${ }^{2}$ and Sasheela Ponnampalavanar ${ }^{2^{*}}$

\begin{abstract}
Background: Methicillin-resistant Staphylococcus aureus (MRSA) is an established pathogen that causes hospital- and community-acquired infections worldwide. The prevalence rate of MRSA infections were reported to be the highest in Asia. As there is limited epidemiological study being done in Malaysia, this study aimed to determine the prevalence of MRSA infection and the molecular characteristics of MRSA bacteraemia.

Methods: Two hundred and nine MRSA strains from year 2011 to 2012 were collected from a tertiary teaching hospital in Malaysia. The strains were characterized by antimicrobial susceptibility testing, staphylococcal cassette chromosome mec (SCCmec) typing, detection of Panton-Valentine leukocidin (PVL) gene, multilocus sequence typing (MLST) and pulsed-field gel electrophoresis (PFGE). Patient's demographic and clinical data were collected and correlated with molecular data by statistical analysis.
\end{abstract}

Results: Male gender and patient $>50$ years of age $(p<0.0001)$ were significantly associated with the increased risk of MRSA acquisition. Fifty-nine percent of MRSA strains were HA-MRSA that carried SCCmec type II, III, IV and V while 31\% were CA-MRSA strains with SCCmec III, IV and V. The prevalence of PVL gene among 2011 MRSA strains was 5.3\% and no PVL gene was detected in 2012 MRSA strains. All of the strains were sensitive to vancomycin. However, vancomycin MIC creep phenomenon was demonstrated by the increased number of MRSA strains with MIC $\geq 1.5 \mu \mathrm{g} / \mathrm{mL}(p=0.008)$ between 2011 and 2012. Skin disease $(p=0.034)$ and SCCmec type III $(p=0.0001)$ were found to be significantly associated with high vancomycin MIC. Forty-four percent of MRSA strains from blood, were further subtyped by MLST and PFGE. Most of the bacteraemia cases were primary bacteraemia and the common comorbidities were diabetes, hypertension and chronic kidney disease. The predominant pulsotype was pulsotype C exhibited by SCCmec III-ST239. This is a first study in Malaysia that reported the occurrence of MRSA clones such as SCCmec V-ST5, untypeable-ST508, SCCmec IV-ST1 and SCCmec IV-ST1137.

Conclusions: SCCmec type III remained predominant among the MRSA strains in this hospital. The occurrence of SCCmec IV and V among hospital strains and the presence of SCCmec III in CA-MRSA strains are increasing. MRSA strains causing bacteraemia over the two-year study period were found to be genetically diverse.

Keywords: Methicillin-resistant Staphylococcus aureus (MRSA), SCCmec types, MLST, PFGE, MRSA Bacteraemia

\footnotetext{
* Correspondence: sheela@ummc.edu.my

${ }^{2}$ Department of Medicine, Faculty of Medicine, University of Malaya, 50603

Kuala Lumpur, Malaysia

Full list of author information is available at the end of the article
} 


\section{Background}

Methicillin-resistant Staphylococcus aureus (MRSA) is widely recognized as one of the pathogens causing hospital- and community- acquired infections. MRSA is highly prevalent in hospitals worldwide in which high rates $(>50 \%)$ were reported in Asia, Malta, North and South America [1]. The prevalence of MRSA in Malaysia ranged from $17 \%$ in 1986 [2] to $44.1 \%$ in 2007 [3]. MRSA is evolved from methicillin-susceptible $S$. aureus through the acquisition of Staphylococcal cassette chromosome mec (SCCmec) which carries mecA gene. $m e c \mathrm{~A}$ gene encodes the penicillin-binding protein (PBP2a) which confers resistance to all $\beta$-lactam antibiotics [4].

Hospital-acquired (HA)-MRSA strains cause nosocomial infections and are associated with SCCmec type I, II or III. In the 1990s, the epidemiology of MRSA infections has changed due to the emergence of communityacquired (CA)-MRSA strains. CA-MRSA strains cause skin and soft tissue infections (SSTIs), sepsis, osteomyelitis, necrotizing pneumonia and fasciitis and pyomyositis in children, soldiers, professional football players or incarcerated populations. They often carry Panton-Valentine leukocidin (PVL) genes and SCCmec IV or V $[4,5]$. To date, eleven different SCCmec types (I-XI) have been defined [6]. However, only SCCmec type I-V are globally distributed while others are uncommon and may exist as local strains in their original country [7].

There are various discriminative methods to type MRSA and to determine its molecular epidemiology. These methods include SCCmec typing, pulsed-field gel electrophoresis (PFGE) and multilocus sequence typing (MLST) [1]. In brief, SCCmec polymerase chain reaction (PCR) typing allows the presumptive assignment of all SCCmec types to MRSA strains which differentiates between HA-MRSA and CA-MRSA [8]. PFGE is based on DNA fingerprints generated by rare restriction endonuclease digestion and is useful for investigating nosocomial outbreaks as well as to identify MRSA strains that may cause major outbreaks. MLST is a highly discriminatory method used for the investigation of the molecular evolution of MRSA. It is based on the sequences of 450-bp internal fragments of 7 housekeeping genes amplified by PCR. The sequences of the genes are compared to those in MLST website (http://www.mlst.net) which results in an allelic profile or sequence type (ST). By using the eBURST software (http://eburst.mlst.net/ v3/mlst_datasets/), clonal complex (CC) can be defined based upon the STs, in which the evolutionary events can be analyzed $[8,9]$.

The most prevalent CCs reported worldwide are CC8 (ST239), CC5 (ST5) and CC22 (ST22) [1]. Numerous genetic linkages of CA-MRSA have been reported to be globally distributed. These include ST30-IV, ST8-IV, ST1-IV, ST59-V and ST80-IV [10]. Previous studies done by Lim et al. [11, 12] on 2003 and 2008 MRSA isolates in this same tertiary teaching hospital and on 2008 to 2010 MRSA isolates in a tertiary hospital in Terengganu had reported SCCmec type III and MLST type ST239 to be the predominant clone. Similar findings were also reported by Ghaznavi-Rad et al. [13], where $90 \%$ of MRSA infections in another tertiary hospital belonged to MLST type ST239. CA-MRSA strains in Malaysian hospitals were reported to belong to SCCmec type IV-MLST type ST30 based on study done by Ahmad et al. [3] on 2006 and 2008 MRSA strains from nine Malaysian hospitals.

Nosocomial bacteraemia has been reported to be common in hospitals worldwide leading to high mortality rate [14] and in Malaysia, 21\% cases of bacteraemia were reported to be caused by MRSA [15]. International MRSA clones such as ST22-SCCmec IV, ST239-SCCmec III, ST5-SCCmec II [16] ST30-SCCmec IV and ST1-SCCmec IV [17] were reported to be spreading around the world, disseminating between and within the countries. HA-MRSA strains had also been found circulating in the community and CA-MRSA strains were reported to cause the outbreak of HA infections [18]. These epidemiological changes in MRSA have posed great threat to the public health. However, limited epidemiological studies have been done in Malaysian hospitals to monitor the trends in MRSA infections. The importance of continuous surveillance programs and molecular epidemiological studies; apart from proper infection control practices and antibiotic stewardship in designing effective and rational pathogen control strategies in hospitals were highlighted in an example of decreased rate of MRSA infections in Japan and Taiwan from $71.6 \%$ in 2001 to $41 \%$ in 2011 and $68.8 \%$ in 2000 to $55.9 \%$ in 2010 , respectively [19] Therefore, the objectives of the study were to characterize the MRSA strains from year to 2011 to 2012 and to determine the characteristics of MRSA bacteraemia in the tertiary teaching hospital by molecular typing such as SCCmec and PVL PCR typing, MLST and PFGE.

\section{Methods}

\section{Setting}

UMMC is a 980-bed referral and teaching hospital in Malaysia consisting of intensive care units, paediatric, orthopaedic, surgical, medical, obstetrics and gynaecology and psychiatry wards and clinics.

\section{Bacterial strains}

All adult patients ( $>16$ years old) who fulfilled the criteria for MRSA infection were included in this study. This study was approved by Medical Ethic Committee of University Malaya Medical Centre (UMMC) on 7th June 
2014 (MEC ID: 20145-168). A total of 209 nonduplicate MRSA clinical strains were collected retrospectively from University Malaya Medical Centre (UMMC). The strains were previously isolated from sterile sites such as cerebrospinal fluid (CSF), synovial fluid, tissue, bone, pus and blood in January 2011 to December 2012. Only strains from pus that was clinically significant and obtained in an aseptic manner either in operation theatre (OT) or procedure room was included in this study. The identities of the strains were confirmed with PCR targeting femA gene and identified as MRSA using standard microbiological methods such as tube coagulase test, DNase and cefoxitin disk (FOX) screen test.

These strains were characterized using antimicrobial susceptibility testing, SCCmec typing and PCR targeting PVL gene. Ninety-one selected strains isolated from blood were further subtyped by PFGE and MLST.

\section{Antimicrobial susceptibility testing}

Vancomycin minimum inhibitory concentration (MIC) results based on E-test were collected from the hospital's microbiology diagnostic laboratory. The interpretation was done according to Clinical and Laboratory Standards Institute (CLSI) guidelines.

\section{SCCmec typing and PCR-based assays for PVL gene}

Crude genomic DNA was extracted by using simple boiling method and the supernatant was used as DNA template for PCR analysis. The cycling condition and primers as described by Milheirico et al. [20] were used to detect SCCmec types. For further subgrouping SCCmec type IV strains, the cycling condition as described by Milheirico et al. [21] and specific primers 4a1, 4a2, 4b1, 4b2, 4c1, 4c2, 4d1 and 4d2 as described by Zhang et al. [22] were used. The following strains: 85/ 2082 (SCCmec type III), JCSC2172 (SCCmec type IVb), JCSC4744 (SCCmec type IVa), JCSC4469 (SCCmec type IVd), MR108 (SCCmec type IVc), N315 (SCCmec type II), NCTC10442 (SCCmec type I) and WIS (SCCmec type V) were kindly provided by K.L. Thong, University of Malaya and used as positive control strains to optimize the multiplex PCR assay. The detection of PVL gene was performed as described by Holmes et al. [23] with slight modification. Briefly, the amplification was performed in a final volume of $25 \mu \mathrm{l}$ containing $2 \mu \mathrm{l}$ of DNA template, $1 \mathrm{X}$ PCR buffer, $1.5 \mathrm{mM} \mathrm{MgCI}_{2}, 0.2 \mathrm{mM}$ dNTPs, $0.5 \mu \mathrm{l}$ of Taq polymerase (Promega Corporation, USA) and $0.2 \mu \mathrm{l}$ of primers $l u k-P V-1$ and $l u k-P V-2$ (Integrated DNA Technologies, USA). The cycling conditions were as described and the PCR products were analyzed by electrophoresis in a $1 \%$ agarose gel.

\section{MLST and PFGE}

MLST was performed as previously described by Enright et al. [24]. The sequence types (STs) were assigned by comparing the sequences of each locus to those in the $S$. aureus MLST database (http://saureus.mlst.net) and clonal complexes were defined by eBURST program.

PFGE was performed according to the Centers for Disease Control and Prevention (CDC) PulseNet protocol [25] with slight modification. In brief, a single colony of bacteria was streaked onto TSA (BD Difco ${ }^{\mathrm{Tm}}$ ) and incubated at $37{ }^{\circ} \mathrm{C}$ overnight. An aliquot of $100 \mu \mathrm{l}$ of bacterial cell suspension (containing bacterial culture in cell suspension buffer) was transferred to a microcentrifuge tube and added with lysostaphin $(1 \mathrm{mg} / \mathrm{mL})$ and lysozyme $(10 \mathrm{mg} / \mathrm{mL})$ (Sigma-Aldrich, USA). Following incubation at $37{ }^{\circ} \mathrm{C}$, proteinase $\mathrm{K}(20 \mathrm{mg} / \mathrm{mL}$ ) (Promega Corporation, USA) and $1 \%$ seakem gold agarose (Lonza, USA) were added into the suspension, mixed and allowed to solidify in a plug mold. The plug was transferred into cell lysis buffer (CLB), incubated at $54{ }^{\circ} \mathrm{C}$ for $3 \mathrm{~h}$ and washed with sterile distilled water and TE buffer. A slice of plug was cut and digested with SmaI (Promega Corporation, USA) followed by separation on CHEF MAPPER in 0.5X TBE at $14{ }^{\circ} \mathrm{C}$ for $22 \mathrm{~h}$ with pulse time of $5-60$ s. The Salmonella ser. Branderup isolate H9812 was used as the reference strain. The gel was stained in Gel Red dye (Biotium, USA) and visualized under BioRad GelDoc XR. BioNumerics 6.5 Software package was used for cluster analyses of PFGE profiles based on the unweighted pair group method with arithmetic averages (UPGMA) with a tolerance of $1.5 \%$ and optimization of $1 \%$. The PFGE profile was assigned an arbitrary designation and the Dice coefficient of similarity, $F$ defined the differences [11].

\section{Clinical data collection}

Patient's demographic and clinical data such as age, gender, diagnosis, comorbidities, site of infection, healthcare- associated risk factors were collected from the hospital's medical record unit. Based on the CDC definitions, HA-MRSA is defined as positive culture obtained more than $48 \mathrm{~h}$ after hospital admission, or history of previous hospitalization or medical procedures. CA-MRSA refers to cases with positive culture obtained less than $48 \mathrm{~h}$ of admission without healthcare-associated risk factors $[18,26]$. In this study, MRSA infection were defined as HA- or CA- MRSA based upon the data collected from patient's clinical notes and from the Infection Control Department's database on multidrug resistant organisms (MDROs). By using these two sources, the risk factors for HA- and CA- MRSA infections were identified with reasonable accuracy. 
Table 1 Comparisons between the patients' demographics, phenotypic and genotypic characteristics of HA-MRSA and CA-MRSA in 2011 and 2012

\begin{tabular}{|c|c|c|c|c|c|}
\hline & 2011 & 2012 & \multirow{2}{*}{$\begin{array}{l}P \\
\text { value }\end{array}$} & Total & \multirow[t]{2}{*}{$P$ value } \\
\hline & $N=95(\%)$ & $N=114(\%)$ & & $N=209(\%)$ & \\
\hline \multicolumn{6}{|l|}{ Age } \\
\hline$\leq 50$ years old & $39(41.1)$ & $27(23.7)$ & 0.011 & 66 (31.6) & \multirow[t]{3}{*}{$<0.0001$} \\
\hline$>50$ years old & $52(54.7)$ & $86(75.4)$ & 0.002 & $138(66)$ & \\
\hline Not Known & $4(4.2)$ & $1(0.9)$ & & $5(2.4)$ & \\
\hline \multicolumn{6}{|l|}{ Gender } \\
\hline Female & $30(31.6)$ & $44(38.6)$ & 0.312 & 74 (35.4) & \multirow[t]{3}{*}{$<0.0001$} \\
\hline Male & $62(65.3)$ & $70(61.4)$ & 0.666 & $132(63.2)$ & \\
\hline Not Known & $3(3.2)$ & $0(0)$ & & $3(1.4)$ & \\
\hline \multicolumn{6}{|l|}{ Source } \\
\hline Blood & $40(42.1)$ & $51(44.7)$ & 0.780 & $91(43.5)$ & \\
\hline Tissue & 37 (38.9) & $42(36.8)$ & 0.776 & 79 (37.8) & \\
\hline CSF & $3(3.2)$ & $0(0)$ & 0.092 & $3(1.4)$ & \\
\hline Pus, slough \& Abscess & $8(8.4)$ & $11(9.6)$ & 0.813 & $19(9.1)$ & \\
\hline Pericardial fluid & $1(1.1)$ & $0(0)$ & 0.455 & $1(0.5)$ & \\
\hline Bullae fluid & $0(0)$ & $1(0.9)$ & 1.000 & $1(0.5)$ & \\
\hline Synovial fluid & $2(2.1)$ & $2(1.8)$ & 1.000 & $4(1.9)$ & \\
\hline Bone & $4(4.2)$ & $7(6.1)$ & 0.758 & $11(5.3)$ & \\
\hline \multicolumn{6}{|l|}{ SCCmec types } \\
\hline sccmec I & $0(0)$ & $0(0)$ & & $0(0)$ & \\
\hline sccmec II & $2(2.1)$ & $0(0)$ & 0.205 & $2(0.9)$ & \\
\hline sccmec III & $61(64.2)$ & $78(68.4)$ & 0.558 & $139(66.5)$ & \\
\hline \multicolumn{6}{|l|}{ SCCmec IV } \\
\hline scCmec IVa & $5(5.3)$ & $4(3.5)$ & 0.735 & $9(4.3)$ & \\
\hline sccmec IVb & $5(5.3)$ & $0(0)$ & 0.018 & $5(2.4)$ & \\
\hline sccmec IVc & $0(0)$ & $0(0)$ & & $0(0)$ & \\
\hline scCmec IVd & $0(0)$ & $0(0)$ & & $0(0)$ & \\
\hline Novel subtypes & $15(15.8)$ & $30(26.3)$ & 0.090 & 45 (21.5) & \\
\hline sccmec V & $6(6.3)$ & $1(0.9)$ & 0.048 & $7(3.3)$ & \\
\hline Untypeable & $1(1.1)$ & $1(0.9)$ & 1.000 & $2(0.9)$ & \\
\hline \multicolumn{6}{|l|}{ Type of MRSA } \\
\hline HA-MRSA & $44(46.3)$ & 79 (69.3) & 0.001 & $123(58.9)$ & \\
\hline sccmec II & $2(4.5)$ & $0(0)$ & 0.126 & $2(1.6)$ & \\
\hline sccmec III & $35(79.5)$ & $56(70.9)$ & 0.392 & 91 (73.9) & \\
\hline \multicolumn{6}{|l|}{ scCmec IV } \\
\hline scCmec IVa & $1(2.3)$ & $3(3.8)$ & 1.000 & $4(3.3)$ & \\
\hline scCmec IVb & $3(6.8)$ & $0(0)$ & 0.044 & $3(2.4)$ & \\
\hline Novel subtypes & $3(6.8)$ & $19(24.1)$ & 0.025 & $22(17.9)$ & \\
\hline sccmec V & $0(0)$ & $1(1.3)$ & 1.000 & $1(0.8)$ & \\
\hline CA-MRSA & $41(43.2)$ & $24(21.1)$ & 0.001 & $65(31.1)$ & \\
\hline sccmec III & $23(56.1)$ & $13(54.2)$ & 1.000 & $36(55.4)$ & \\
\hline
\end{tabular}


Table 1 Comparisons between the patients' demographics, phenotypic and genotypic characteristics of HA-MRSA and CA-MRSA in 2011 and 2012 (Continued)

\begin{tabular}{|c|c|c|c|c|}
\hline SCCmec IVa & $4(9.8)$ & $1(4.2)$ & 0.644 & $5(7.7)$ \\
\hline scCmec IVb & $2(4.9)$ & $0(0)$ & 0.527 & $2(3.1)$ \\
\hline Novel subtypes & $7(17.1)$ & $10(41.7)$ & 0.042 & $17(26.2)$ \\
\hline sccmec V & $4(9.8)$ & $0(0)$ & 0.288 & $4(6.2)$ \\
\hline Untypeable & $1(2.4)$ & $0(0)$ & 1.000 & $1(1.5)$ \\
\hline Not Known & $10(10.5)$ & $11(9.6)$ & & $21(10)$ \\
\hline scCmec III & $3(30)$ & $9(81.8)$ & & $12(57.1)$ \\
\hline \multicolumn{5}{|l|}{ sccmec IV } \\
\hline Novel subtypes & $5(50)$ & $1(9.1)$ & & $6(28.6)$ \\
\hline sccmec V & $2(20)$ & $0(0)$ & & $2(9.5)$ \\
\hline Untypeable & $0(0)$ & $1(9.1)$ & & $1(4.8)$ \\
\hline PVL gene & $5(5.3)$ & $0(0)$ & 0.018 & $5(2.4)$ \\
\hline \multicolumn{5}{|l|}{ Vancomycin MIC } \\
\hline$<1.5 \mu \mathrm{g} / \mathrm{mL}$ & $58(61.1)$ & $48(42.1)$ & 0.008 & $106(50.7)$ \\
\hline$\geq 1.5 \mu \mathrm{g} / \mathrm{mL}$ & 37 (38.9) & $66(57.9)$ & & $103(49.3)$ \\
\hline
\end{tabular}

CSF Cerebrospinal fluid

Fisher's exact test done for categorical variables, $p$ value $<0.05$ was considered to be statistical significant and are indicated by bold text

\section{Statistical analysis}

Categorical data were compared using Fisher exact test. All reported $p$ values are two-tailed and analyses were performed using GraphPad software (https://www.graph pad.com/quickcalcs/catMenu/). Variables with $p<0.05$ were considered to be statistically significant.

\section{Results}

\section{Distribution of MRSA strains}

In this study, 209 MRSA strains from year 2011 to 2012 were collected from various clinical specimens including tissues ( $n=79 ; 37.8 \%$ ), blood $(n=91 ; 43.5 \%)$, pus, slough and abscess $(n=19 ; 9.1 \%)$, cerebrospinal fluid ( $n=3 ; 1.4 \%)$, bone $(n=11 ; 5.3 \%)$, pericardial fluid $(n=1 ; 0.5 \%)$, bullae fluid $(n=1 ; 0.5 \%)$ and synovial fluid $(n=4 ; 1.9 \%)$. The median age was 58 years old ranging from 16 to 92 years old and most cases belonged to the age group of 51-92 years. MRSA infections were significantly decreased in the age group of $\leq 50$ years old (41.1\% in 2011 vs $23.7 \%$ in 2012) ( $p=0.011$ ) while an increase was seen in the age group of $>50$ years old (54.7\% in 2011 vs $75.4 \%$ in 2012$)(p=0.002)$. A total of $132(63.2 \%)$ specimens were collected from male, 74 $(35.4 \%)$ were from female and 3 specimens were unknown. Age $>50$ years old and male gender $(p<0.0001)$ were the significant risk factors in the acquisition of MRSA.

Fifty-nine percent (123 of 209) of MRSA strains were HA-MRSA, 31\% (65 of 209) were of CA-MRSA and the remaining MRSA strains were not known. Some of the MRSA strains had incomplete clinical data such as unknown age, gender and MRSA types because the patient's medical records could not be retrieved from the archived records. HA- and CA- MRSA infections were significantly increased and decreased from year 2011 to $2012(p=0.001)$ respectively (Table 1$)$.

\section{Antimicrobial susceptibility testing}

All the MRSA strains were sensitive to vancomycin with the vancomycin MICs ranged from $0.38-2 \mu \mathrm{g} / \mathrm{mL}$. One hundred and six (50.7\%) and 103 (49.3\%) out of 209 strains had vancomycin $\mathrm{MIC}<1.5 \mu \mathrm{g} / \mathrm{mL}$ and $\geq 1.5 \mu \mathrm{g} / \mathrm{mL}$, respectively. A significant decreased was observed in the number of strains with $\mathrm{MIC}<1.5 \mu \mathrm{g} / \mathrm{mL}$ (61.1\% in 2011 vs $42.1 \%$ in 2012) and an increase was seen in the number of strains with $\mathrm{MIC} \geq 1.5 \mu \mathrm{g} / \mathrm{mL}$ (38.9\% in 2011 vs $57.9 \%$ in 2012) ( $p=0.008)$. Comparisons of patient demographics, clinical features and the genotypes between the low $(<1.5 \mu \mathrm{g} / \mathrm{mL})$ and high $(\geq 1.5 \mu \mathrm{g} / \mathrm{mL})$ vancomycin $\mathrm{MIC}$ groups were shown in Table 2 . There were no significant differences in terms of age, gender and clinical diagnosis. However, skin disease $(p=0.034)$ and SCCmec type III $(p=0.0001)$ were found to be strongly associated with elevated MIC ( $\geq 1.5 \mu \mathrm{g} / \mathrm{mL})$, while SCCmec type IV was associated with low vancomycin MIC $(p=0.0001)$ (Table 2).

\section{SCCmec types and the presence of PVL gene}

For year 2011 MRSA strains, the predominant SCCmec type was SCCmec type III $(n=61 ; 64.2 \%)$. A total of 25 MRSA strains were SCCmec type IV and further subtyped into SCCmec type IVa $(n=5 ; 5.3 \%)$ and SCCmec type IVb $(n=5 ; 5.3 \%)$. Fifteen MRSA strains could not be subtyped and were known as 
Table 2 Comparison between the vancomycin MICs with patient's demographics, clinical diagnosis and genotypic characteristics of MRSA in 2011 and 2012

\begin{tabular}{|c|c|c|c|c|c|c|c|}
\hline & \multicolumn{7}{|c|}{ Vancomycin MIC } \\
\hline & \multicolumn{3}{|l|}{$<1.5 \mu \mathrm{g} / \mathrm{mL}$} & \multicolumn{3}{|l|}{$\geq 1.5 \mu \mathrm{g} / \mathrm{mL}$} & \multirow[t]{3}{*}{$P$ value } \\
\hline & 2011 & 2012 & Total & 2011 & 2012 & Total & \\
\hline & $N=58(\%)$ & $N=48(\%)$ & $N=106(\%)$ & $N=37(\%)$ & $N=66(\%)$ & $N=103(\%)$ & \\
\hline \multicolumn{8}{|l|}{ Age } \\
\hline$\leq 50$ years old & $26(44.8)$ & $8(16.7)$ & $34(32.1)$ & $13(35.1)$ & 19 (28.8) & $32(31.1)$ & 0.883 \\
\hline$>50$ years old & $29(50)$ & $40(83.3)$ & $69(65.1)$ & $23(62.2)$ & $46(69.7)$ & $69(66.9)$ & 0.884 \\
\hline Not Known & $3(5.2)$ & $0(0)$ & $3(2.8)$ & $1(2.7)$ & $1(1.5)$ & $2(1.9)$ & \\
\hline \multicolumn{8}{|l|}{ Gender } \\
\hline Female & $18(31)$ & $22(45.8)$ & $40(37.7)$ & $12(32.4)$ & $22(33.3)$ & $34(33)$ & 0.563 \\
\hline Male & $38(65.5)$ & $26(54.2)$ & $64(60.4)$ & $24(64.9)$ & $44(66.7)$ & $68(66)$ & 0.474 \\
\hline Not Known & $2(3.4)$ & $0(0)$ & $2(1.9)$ & $1(2.7)$ & $0(0)$ & $1(0.9)$ & \\
\hline \multicolumn{8}{|l|}{ Clinical diagnosis } \\
\hline Bacteraemia & $25(43.1)$ & $24(50)$ & $49(46.2)$ & $15(40.5)$ & $27(40.9)$ & $42(40.8)$ & 0.486 \\
\hline Skin and soft tissue infections & $26(44.8)$ & $20(41.7)$ & $46(43.4)$ & $20(54.1)$ & $3146.9)$ & $51(49.5)$ & 0.407 \\
\hline Osteomyelitis or septic arthritis & $3(5.2)$ & $3(6.3)$ & $6(5.7)$ & $2(5.4)$ & $7(10.6)$ & $9(8.7)$ & 0.432 \\
\hline Meningitis & $3(5.2)$ & $0(0)$ & $3(2.8)$ & $0(0)$ & $1(1.5)$ & $1(0.9)$ & 0.622 \\
\hline Pericarditis & $1(1.7)$ & $1(2.1)$ & $2(1.9)$ & $0(0)$ & $0(0)$ & $0(0)$ & 0.498 \\
\hline \multicolumn{8}{|l|}{ Co-morbidities } \\
\hline Diabetes mellitus & $12(20.7)$ & $27(56.3)$ & $39(36.8)$ & $12(32.4)$ & $25(37.9)$ & $37(35.9)$ & 1.000 \\
\hline Hypoglycaemia & $1(1.7)$ & $0(0)$ & $1(0.9)$ & $0(0)$ & $0(0)$ & $0(0)$ & 1.000 \\
\hline Hypertension & $12(20.7)$ & $24(50)$ & $36(33.9)$ & $11(29.7)$ & $23(34.8)$ & $34(33)$ & 1.000 \\
\hline Obesity & $0(0)$ & $1(2.1)$ & $1(0.9)$ & $0(0)$ & $0(0)$ & $0(0)$ & 1.000 \\
\hline Chronic kidney disease and UTI & $9(15.5)$ & 19 (39.6) & $28(26.4)$ & $5(13.5)$ & $25(37.9)$ & $30(29.1)$ & 0.758 \\
\hline Cancer & $8(13.8)$ & $6(12.5)$ & $14(13.2)$ & $3(8.1)$ & $2(3)$ & $5(4.9)$ & 0.052 \\
\hline Head injury & $3(5.2)$ & $10(20.8)$ & $13(12.3)$ & $6(16.2)$ & $10(15.2)$ & $16(15.5)$ & 0.552 \\
\hline Liver disease & $1(1.7)$ & $5(10.4)$ & $6(5.7)$ & $0(0)$ & $2(3)$ & $2(1.9)$ & 0.280 \\
\hline Respiratory disease & $7(12.1)$ & $9(18.8)$ & $16(15.1)$ & $3(8.1)$ & $10(15.2)$ & $13(12.6)$ & 0.691 \\
\hline Cardiovascular disease & $6(10.3)$ & $11(22.9)$ & $17(16)$ & $2(5.4)$ & $8(12.1)$ & $10(9.7)$ & 0.217 \\
\hline Gastrointestinal disease & $2(3.4)$ & $3(6.3)$ & $5(4.7)$ & $0(0)$ & $2(3)$ & $2(1.9)$ & 0.446 \\
\hline Autoimmune disease & $1(1.7)$ & $0(0)$ & $1(0.9)$ & $0(0)$ & $0(0)$ & $0(0)$ & 1.000 \\
\hline Bone and joint disorder & $3(5.2)$ & $4(8.3)$ & $7(6.6)$ & $0(0)$ & $6(9.1)$ & $6(5.8)$ & 1.000 \\
\hline Endocrine disorder & $0(0)$ & $2(4.2)$ & $2(1.9)$ & $0(0)$ & $1(1.5)$ & $1(0.9)$ & 1.000 \\
\hline Blood disorder & $1(1.7)$ & $1(2.1)$ & $2(1.9)$ & $0(0)$ & $2(3)$ & $2(1.9)$ & 1.000 \\
\hline CMV & $0(0)$ & $1(2.1)$ & $1(0.9)$ & $0(0)$ & $0(0)$ & $0(0)$ & 1.000 \\
\hline Skin disease & $0(0)$ & $1(2.1)$ & $1(0.9)$ & $4(10.8)$ & $3(4.5)$ & $7(6.8)$ & 0.034 \\
\hline None & $3(5.2)$ & $4(8.3)$ & 7 (6.6) & $0(0)$ & $4(6.1)$ & $4(3.9)$ & 0.538 \\
\hline Not Known & $24(41.4)$ & $2(4.2)$ & $26(24.5)$ & $12(32.4)$ & $8(12.1)$ & $20(19.4)$ & 0.407 \\
\hline \multicolumn{8}{|l|}{ sccmec types } \\
\hline sccmec II & $0(0)$ & $0(0)$ & $0(0)$ & $2(5.4)$ & $0(0)$ & $2(1.9)$ & 0.242 \\
\hline sccmec III & $32(55.2)$ & $21(43.8)$ & $53(50)$ & $29(78.4)$ & 57 (86.4) & 86 (83.5) & 0.0001 \\
\hline \multicolumn{8}{|l|}{ sccmec IV } \\
\hline sccmec IVa & $4(6.9)$ & $3(6.3)$ & 7 (6.6) & $1(2.7)$ & $1(1.5)$ & $2(1.9)$ & 0.171 \\
\hline sccmec IVb & $5(8.6)$ & $0(0)$ & $5(4.7)$ & $0(0)$ & $0(0)$ & $0(0)$ & 0.060 \\
\hline
\end{tabular}


Table 2 Comparison between the vancomycin MICs with patient's demographics, clinical diagnosis and genotypic characteristics of MRSA in 2011 and 2012 (Continued)

\begin{tabular}{|c|c|c|c|c|c|c|c|}
\hline Novel subtypes & $13(22.4)$ & $23(47.9)$ & 36 (33.9) & $2(5.4)$ & $7(10.6)$ & $9(8.7)$ & 0.0001 \\
\hline sccmec V & $3(5.2)$ & $1(2.1)$ & $4(3.8)$ & $3(8.1)$ & $0(0)$ & $3(2.9)$ & 1.000 \\
\hline Untypeable & $1(1.7)$ & $0(0)$ & $1(0.9)$ & $0(0)$ & $1(1.5)$ & $1(0.9)$ & 1.000 \\
\hline
\end{tabular}

UTI = Urinary Tract Infection, CMV = Cytomegalovirus

Head injury includes: basal ganglia bleed, subdural hematoma and stroke. Liver disease includes: alcoholic liver disease, liver cirrhosis. Respiratory disease includes: pneumonia, pulmonary embolism, chronic obstructive pulmonary disease, acute respiratory distress syndrome. Cardiovascular disease includes: mitral valve regurgitation, ischaemic heart disease, acute coronary syndrome, congestive cardiac failure. Gastrointestinal disease includes: acute gastroenteritis, Crohn's disease, perforated diverticular disease, intestinal obstruction. Autoimmune disease includes: Systemic lupus erythematosus. Endocrine disorder includes: thyroid disease, primary hypothyroidism. Blood disorder includes: myelofibrosis, anaemia. Skin disease includes: Stevens Johnson Syndrome, Bullous pemphigoid, exfoliative dermatitis and pemphigus vulgaris

Fisher's exact test done for categorical variables, $p$ value $<0.05$ was considered to be statistical significant and are indicated by bold text

novel SCCmec type IV subtypes. There were two and six strains typed as SCCmec type II and SCCmec type V, respectively. For 2012 MRSA strains, three SCCmec types were observed: SCCmec type III $(n=78 ; 68.4 \%)$, SCCmec type IV $(n=34 ; 29.8 \%)$ and SCCmec type V $(n=1 ; 0.9 \%)$. The SCCmec type IV strains were further subtyped as SCCmec type IVa $(n=4 ; 3.5 \%)$ and novel type IV SCCmec subtypes $(n=30 ; 26.3 \%)$. There were two untypeable MRSA strains which harbour mecA gene and no SCCmec type I was found in both years. PVL gene was present in five MRSA strains from 2011 but none was reported in 2012 MRSA strains. All PVL-positive strains were CA-MRSA strains isolated from pus, tissue and abscess and carried SCCmec type IV and V. There was no significant difference in the number of strains carrying SCCmec types II and III. However, a significant decreased in the numbers of SCCmec types IVb $(p=0.018)$ and V $(p=0.048)$ from 2011 to 2012 was observed.

\section{Genotyping by PFGE}

PFGE of SmaI-digested chromosomal DNA of 91 MRSA strains generated 8 pulsotypes $(\mathrm{A}-\mathrm{H})$ each with 13 20 bands, with a Dice coefficient, $F$ ranging from 0.5 to 1.0. Based on $80 \%$ similarity, three clusters (Cluster I to Cluster III) and five singletons were observed. The majority of the strains (64.8\%) were clustered in Cluster II, followed by Cluster I which contained 20 strains (21.9\%) and Cluster III which contained 9 strain (6.6\%). Pulsotype $\mathrm{C}$ in Cluster II was the predominant pulsotype seen with multiple subtypes (C1- C27) and followed by pulsotype A in Cluster I with subtypes (A1-A12). Pulsotype E in Cluster III was less common with fewer subtypes (E1E4) and pulsotypes B, D, F, G and H had no subtypes. Most of the MRSA strains belonged to subtype C11, which was the top major subtype and they were indistinguisable or clonally related. The presence of the clonally or closely related MRSA strains despite being isolated from different wards and different years may suggest the persistence of this clone in this hospital and there was transmission of this clone between wards (Fig. 1).

\section{Determination of clonal relationships by MLST}

MLST analysis revealed eight dfferent sequence types (ST) which include ST239 $(n=61)$, ST22 $(n=19)$, ST508 $(n=1), \operatorname{ST772}(n=1), \operatorname{ST6}(n=6), \operatorname{ST} 5(n=1)$, ST1 $(n=1)$ and ST1137 $(n=1)$. ST6, ST22 and ST239 were observed in MRSA strains of both years, whereas ST5, ST508 and ST772 were present among the 2011 MRSA strains and ST1 and ST1137 were found in 2012 MRSA strains. SCCmec type III belonged to ST239, SCCmec type IV belonged to ST1, ST6, ST22 and ST1137 while SCCmec type V belonged to ST5 and ST772. Strains with untypeable SCCmec were represented by two STs (239 and 508). MRSA strains were clustered into six clonal complexes (CC) based on the similarity between STs in six of seven loci. ST239 was assigned as the putative ancestral genotype of a subgroup within CC8. ST1, ST5, ST6 and ST22 were identified as the ancestral genotypes of their corresponding CCs. The newly discovered clones; ST508 and ST1137 were observed in this study and they belonged to CC45 and CC22, respectively (Fig. 2) (Table 3).

\section{Discussion}

MRSA is known to be one of the most prominent pathogens that causes HA and CA- associated infections in Malaysian hospitals. In this study, 59\% (123 of 209) of MRSA strains were HA-MRSA and 31\% (65 of 209) were of CA-MRSA. Most of the HA-MRSA infections were caused by SCCmec type III $(n=91 ; 73.9 \%)$ strains. Although SCCmec IV and V have been reported to occur in the community [9], most patients seem to acquire these strains in this hospital based on the proportions of SCCmec IV $(n=29 ; 23.6 \%)$ and V $(n=1 ; 0.8 \%)$, indicating the invasion of these strains into hospitals and may replace the classical HA-MRSA strains due to their unique characteristics and faster growth patterns [27]. CA-MRSA infections in this hospital have decreased from 41 to 24 cases in 2011 and 2012, respectively. The high prevalence of SCCmec type III $(n=36 ; 55.4 \%)$ among the CA-MRSA strains might indicate that this MRSA hospital strain has spread to the community. As 


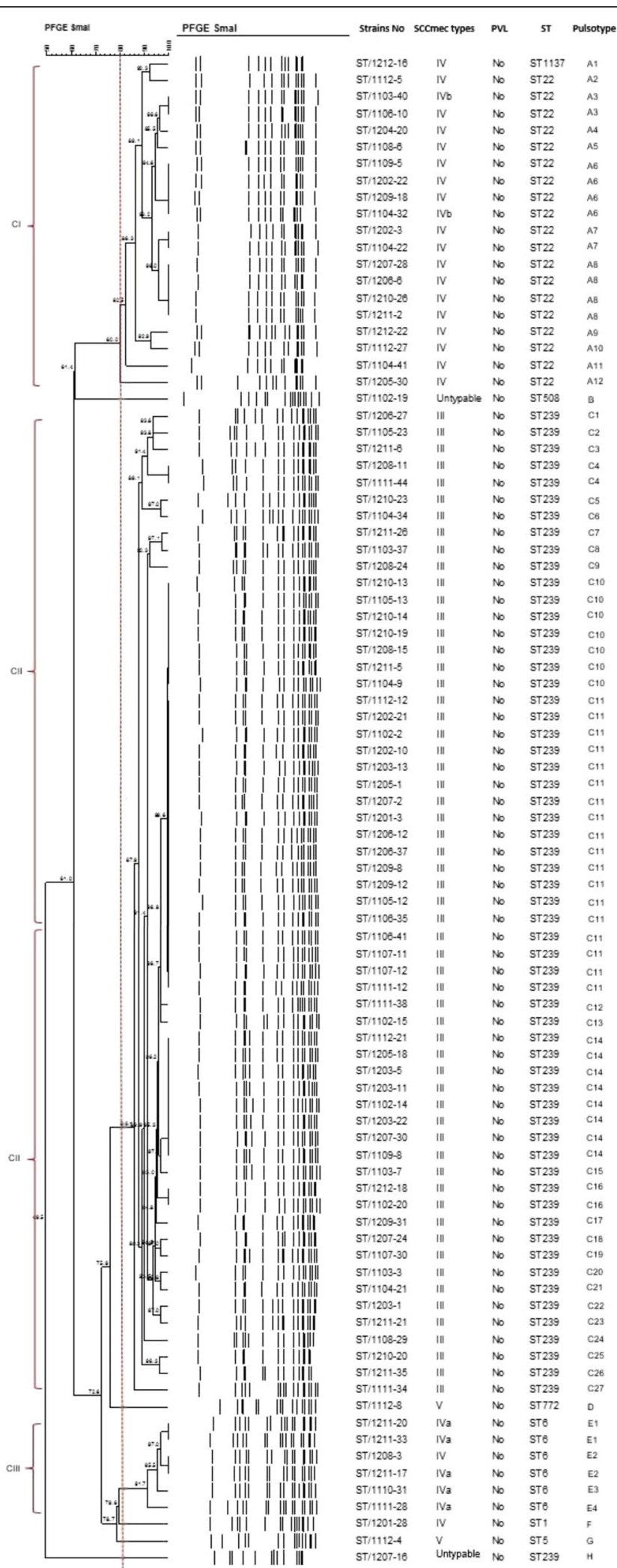

Fig. 1 Dendrogram of MRSA PFGE patterns generated by UPGMA clustering method using Dice coefficient. The dotted line indicates an arbitrary $80 \%$ similarity demarcation 


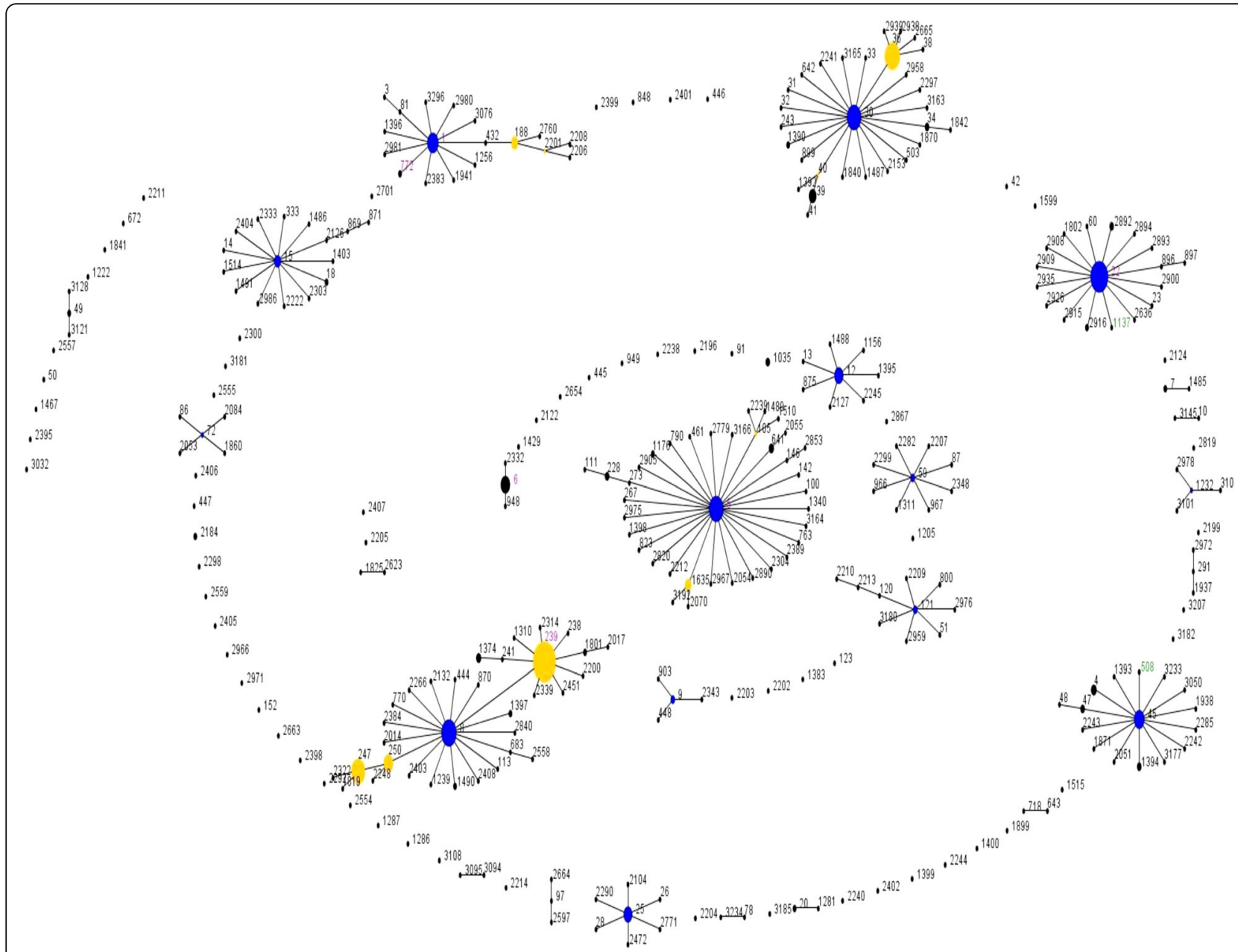

Fig. 2 Population snapshot of MRSA strains from blood source in the MLST database. Individual sequence type (ST) is highlighted in black (STs in the database), green (STs in this study) and pink (STs in both the database and in this study) and is represented by each circle. The size of the circle indicates the frequency of a particular ST and the colour of the circle represents founders or subgroup founders. Blue circles are 'founders' [defined as ST with many single locus variants (SLVS) and is prevalent within a CC], whereas yellow circle are 'subgroup founders'. The most prevalent ST in this study was ST239, which is the subgroup founder within CC8

stated by Chen et al. [28] in a recent study in China, SCCmec III-ST239 is beginning to appear in CA-MRSA isolates. In addition, in the first international surveillance study on the CA-MRSA epidemiology in Asian countries, have revealed the spreading of HA-MRSA isolates to the community, given the presence of SCCmec types I, II and III in CA-MRSA isolates from Taiwan, Korea, Hong Kong, Philippines, Thailand and Vietnam [29]. Based on the distributions analysis in Table 1, MRSA infections were significantly correlated with male patients and between the ages of 51 and 92 years.

The existence of the vancomycin creep phenomenon was demonstrated by the increased percentages of MRSA strains with MIC $\geq 1.5 \mu \mathrm{g} / \mathrm{mL}$ over a 2-year period. In addition, skin disease and SCCmec type III were found to be significantly associated with high vancomycin MIC. This is possibly due to the previous exposure of MRSA strains to vancomycin which led to the changes in the characteristics of bacteria such as bacterial cell wall alterations, preventing vancomycin to reach its target site [30].

SCCmec type III was the predominant SCCmec type for year $2011(n=61 ; 64.2 \%)$ and $2012(n=78 ; 68.4 \%)$ which is consistent with previous reports in Malaysian hospitals done by Lim et al. [11] and Ghaznavi-Rad et al. [13]. SCCmec type III was also common in Asian countries such as Taiwan, Singapore, Thailand and Indonesia [19]. For year 2011 MRSA strains, 25 MRSA strains are SCCmec type IV and were further subtyped as SCCmec type IVa and IVb. Fifteen SCCmec type IV MRSA strains could not be further subtyped and might be the novel type IV SCCmec subtypes. SCCmec types II and V were also observed. For 2012 MRSA strains, other than SCCmec type III, SCCmec type IV and V were also 
Table 3 Comparison between SCCmec types with the patient's demographic, clinical diagnosis and molecular characteristics of MRSA strains isolated from blood

\begin{tabular}{|c|c|c|c|c|c|}
\hline & scCmec III & sccmec IV & scCmec V & Untypeable & $\begin{array}{l}\text { Total } \\
N=91(\%)\end{array}$ \\
\hline & $N=60(\%)$ & $N=27(\%)$ & $N=2(\%)$ & $N=2(\%)$ & $N=91(\%)$ \\
\hline \multicolumn{6}{|l|}{$\overline{\text { Age }}$} \\
\hline$\leq 50$ years old & $12(20)$ & $3(11.1)$ & $0(0)$ & $0(0)$ & $15(16.5)$ \\
\hline$>50$ years old & $47(78.3)$ & $23(85.2)$ & $2(100)$ & $2(100)$ & $74(81.3)$ \\
\hline Not Known & $1(1.7)$ & $1(3.7)$ & $0(0)$ & $0(0)$ & $2(2.2)$ \\
\hline \multicolumn{6}{|l|}{ Gender } \\
\hline Female & $30(50)$ & $10(37)$ & $0(0)$ & $0(0)$ & $40(43.9)$ \\
\hline Male & $29(48.3)$ & $16(59.3)$ & $2(100)$ & $2(100)$ & $49(53.8)$ \\
\hline Not Known & $1(1.7)$ & $1(3.7)$ & $0(0)$ & $0(0)$ & $2(2.2)$ \\
\hline \multicolumn{6}{|l|}{ Co-morbidities } \\
\hline Diabetes mellitus & $20(33.3)$ & $11(40.7)$ & $1(50)$ & $0(0)$ & $32(35.2)$ \\
\hline Hypertension & $22(36.7)$ & $12(44.4)$ & $1(50)$ & $0(0)$ & $35(38.5)$ \\
\hline Obesity & $0(0)$ & $1(3.7)$ & $0(0)$ & $0(0)$ & $1(1.1)$ \\
\hline Chronic kidney disease and UTI & $24(40)$ & $14(51.9)$ & $0(0)$ & $0(0)$ & $38(41.8)$ \\
\hline Cancer & $8(13.3)$ & $2(7.4)$ & $0(0)$ & $0(0)$ & $10(10.9)$ \\
\hline Head injury & $11(18.3)$ & $4(14.8)$ & $0(0)$ & $1(50)$ & $16(17.6)$ \\
\hline Liver disease & $4(6.7)$ & $2(7.4)$ & $0(0)$ & $0(0)$ & $6(6.6)$ \\
\hline Respiratory disease & $12(20)$ & $3(11.1)$ & $1(50)$ & $0(0)$ & $16(17.6)$ \\
\hline Cardiovascular disease & $4(6.7)$ & $8(29.6)$ & $2(100)$ & $0(0)$ & $14(15.4)$ \\
\hline Gastrointestinal disease & $4(6.7)$ & $1(3.7)$ & $0(0)$ & $0(0)$ & $5(5.5)$ \\
\hline Autoimmune disease & $1(1.7)$ & $0(0)$ & $0(0)$ & $0(0)$ & $1(1.1)$ \\
\hline Bone and joint disorder & $1(1.7)$ & $2(7.4)$ & $0(0)$ & $0(0)$ & $3(3.3)$ \\
\hline Endocrine disorder & $0(0)$ & $2(7.4)$ & $0(0)$ & $0(0)$ & $2(2.2)$ \\
\hline Blood disorder & $2(3.3)$ & $0(0)$ & $0(0)$ & $0(0)$ & $2(2.2)$ \\
\hline CMV & $1(1.7)$ & $0(0)$ & $0(0)$ & $0(0)$ & $1(1.1)$ \\
\hline Skin disease & $7(11.7)$ & $0(0)$ & $0(0)$ & $0(0)$ & $7(7.7)$ \\
\hline None & $1(1.7)$ & $0(0)$ & $0(0)$ & $0(0)$ & $1(1.1)$ \\
\hline Not known & $7(11.7)$ & $5(18.5)$ & $0(0)$ & $1(50)$ & $13(14.3)$ \\
\hline \multicolumn{6}{|l|}{ No of comorbidities } \\
\hline 0 & $8(13.3)$ & $5(18.5)$ & $0(0)$ & $1(50)$ & $14(15.4)$ \\
\hline 1 & $19(31.7)$ & $5(18.5)$ & $1(50)$ & $1(50)$ & $26(28.6)$ \\
\hline 2 & $11(18.3)$ & $6(22.2)$ & $0(0)$ & $0(0)$ & $17(18.7)$ \\
\hline 3 & $12(20)$ & $1(3.7)$ & $0(0)$ & $0(0)$ & $13(14.3)$ \\
\hline$\geq 4$ & $10(16.7)$ & $10(37)$ & $1(50)$ & $0(0)$ & $21(23.1)$ \\
\hline \multicolumn{6}{|l|}{ Source of bacteraemia } \\
\hline Primary bacteraemia & $38(63.3)$ & $19(70.4)$ & $2(100)$ & $2(100)$ & $61(67)$ \\
\hline Catheter-related & $7(11.7)$ & $5(18.5)$ & $0(0)$ & $0(0)$ & $12(13.2)$ \\
\hline Skin and soft tissue infection & $6(10)$ & $0(0)$ & $0(0)$ & $0(0)$ & $6(6.6)$ \\
\hline Surgical site infection & $1(1.7)$ & $0(0)$ & $0(0)$ & $0(0)$ & $1(1.1)$ \\
\hline Pneumonia & $5(8.3)$ & $2(7.4)$ & $0(0)$ & $0(0)$ & $7(7.7)$ \\
\hline Implant-related infection & $0(0)$ & $1(3.7)$ & $0(0)$ & $0(0)$ & $1(1.1)$ \\
\hline More than one source & $3(5)$ & $0(0)$ & $0(0)$ & $0(0)$ & $3(3.3)$ \\
\hline
\end{tabular}


Table 3 Comparison between SCCmec types with the patient's demographic, clinical diagnosis and molecular characteristics of MRSA strains isolated from blood (Continued)

\begin{tabular}{|c|c|c|c|c|c|}
\hline \multicolumn{6}{|l|}{ Type of MRSA } \\
\hline HA-MRSA & $36(60)$ & 15 (55.6) & $0(0)$ & $0(0)$ & $51(56)$ \\
\hline CA-MRSA & $15(25)$ & $9(33.3)$ & $2(100)$ & $1(50)$ & $27(29.7)$ \\
\hline Not Known & $9(15)$ & $3(11.1)$ & $0(0)$ & $1(50)$ & $13(14.3)$ \\
\hline \multicolumn{6}{|l|}{$\mathrm{CC} / \mathrm{ST}$} \\
\hline \multicolumn{6}{|l|}{$\mathrm{CCl}$} \\
\hline ST1 & $0(0)$ & $1(3.7)$ & $0(0)$ & $0(0)$ & $1(1.1)$ \\
\hline ST772 & $0(0)$ & $0(0)$ & $1(50)$ & $0(0)$ & $1(1.1)$ \\
\hline \multicolumn{6}{|l|}{ CC5 } \\
\hline ST5 & $0(0)$ & $0(0)$ & $1(50)$ & $0(0)$ & $1(1.1)$ \\
\hline \multicolumn{6}{|l|}{ CC6 } \\
\hline ST6 & $0(0)$ & $6(22.2)$ & $0(0)$ & $0(0)$ & $6(6.6)$ \\
\hline \multicolumn{6}{|l|}{ CC8 } \\
\hline ST239 & $60(100)$ & $0(0)$ & $0(0)$ & $1(50)$ & $61(67)$ \\
\hline \multicolumn{6}{|l|}{$\mathrm{CC} 22$} \\
\hline ST22 & $0(0)$ & $19(70.4)$ & $0(0)$ & $0(0)$ & 19 (20.9) \\
\hline ST1137 & $0(0)$ & $1(3.7)$ & $0(0)$ & $0(0)$ & $1(1.1)$ \\
\hline \multicolumn{6}{|l|}{ CC45 } \\
\hline ST508 & $0(0)$ & $0(0)$ & $0(0)$ & $1(50)$ & $1(1.1)$ \\
\hline \multicolumn{6}{|l|}{ Vancomycin MIC } \\
\hline$<1.5 \mu \mathrm{g} / \mathrm{mL}$ & $22(36.7)$ & $25(92.6)$ & $1(50)$ & $1(50)$ & $49(53.8)$ \\
\hline$\geq 1.5 \mu \mathrm{g} / \mathrm{mL}$ & $38(63.3)$ & $2(7.4)$ & $1(50)$ & $1(50)$ & $42(46.2)$ \\
\hline
\end{tabular}

UTI = Urinary Tract Infection, CMV = Cytomegalovirus

Head injury includes: basal ganglia bleed, subdural hematoma and stroke. Liver disease includes: alcoholic liver disease, liver cirrhosis. Respiratory disease includes: pneumonia, pulmonary embolism, chronic obstructive pulmonary disease, acute respiratory distress syndrome. Cardiovascular disease includes: mitral valve regurgitation, ischaemic heart disease, acute coronary syndrome, congestive cardiac failure. Gastrointestinal disease includes: acute gastroenteritis, Crohn's disease, perforated diverticular disease, intestinal obstruction. Autoimmune disease includes: Systemic lupus erythematosus. Endocrine disorder includes: thyroid disease, primary hypothyroidism. Blood disorder includes: myelofibrosis, anaemia. Skin disease includes: Stevens Johnson Syndrome, Bullous pemphigoid, exfoliative dermatitis and pemphigus vulgaris

observed. The SCCmec type IV strains are further subtyped as SCCmec type IVa and novel type IV SCCmec subtypes. There were untypeable MRSA strains which harbours mecA gene detected in each year. These strains may indicate new or variant $\mathrm{SCCmec}$ types which should be further analysed [31]. The prevalence of PVL gene among 2011 MRSA strains was 5.3\% and most of them caused skin and soft tissue infections. No PVL gene was detected in year 2012 strains.

MRSA bacteraemia is common in hospitals worldwide, including Malaysia and is associated with high mortality rate and vancomycin treatment failure. Therefore, selected MRSA strains from blood were further typed by MLST and PFGE in order to determine the molecular characteristics of MRSA bacteraemia in both years. In this study, the MRSA yield from blood for both years were accounted for $43.5 \%(n=91)$ with $81.3 \%(n=74)$ recorded in patients aged 51 years and more. Most of the bacteraemia cases were primary bacteraemia $(n=61 ; 67 \%)$. Diabetes $(n=32 ; 35.2 \%)$, hypertension $(n=35 ; 38.5 \%)$ and chronic kidney disease $(n=38 ; 41.8 \%)$ were the most common underlying comorbidities. MRSA bacteraemia were seen to be caused by HA-MRSA strains type III $(n=36)$ and IV $(n=15)$ and CA-MRSA strains type III $(n=15), \mathrm{IV}(n=9)$ and $\mathrm{V}(n=2)$ as shown in Table 3. Analysis of the PFGE patterns have supported the possibility of the spread of SCCmec type III-ST239 into the community as they are closely related to the HA-MRSA clone of SCCmec type III-ST239. Whereas, SCCmec type IV strains were seen to have invaded and resided in this hospital as nosocomial MRSA strains. Due to their multiplication and transmission rates, there is a possibility for these type IV strains to replace and become the predominant endemic MRSA clone in this hospital [32].

Based on the PFGE dendrogram, 20 MRSA strains within Cluster I were closely related as they shared more than $80 \%$ similarity. Although they were from different years, they shared the same characteristics of having SCCmec type IV and ST22. MRSA strain of SCCmec type IV-ST1137 was also assigned in this cluster because 
ST1137 was shown to belong in the same CC as ST22. Another six SCCmec type IV MRSA strains were assigned in Cluster III as they shared similar characteristic of having MLST ST6. Most novel SCCmec type IV strains $(n=18)$ were assigned in the same Cluster I as SCCmec type IVb. SCCmec type IVa displayed no epidemiological linkage with SCCmec type IVb. There was a substantial genetic diversity in SCCmec type IV by the presence of various sequence types (ST1, ST5, ST6, ST22 and ST1137) indicating its capability to transfer between different genetic clones of $S$. aureus. All the MRSA strains that possessed SCCmec type III-ST239 were distributed in Cluster II.

The two SCCmec type V strains found in this study were CA-MRSA, PVL negative, had low vancomycin MIC and assigned as singleton due to difference in STs; ST772 and ST5. Previous studies done in the same hospital by Lim et al. [11] and Sam et al. [33] had reported the presence of ST22 and ST6 in SCCmec type IV and ST772 in SCCmec V. However, no local study has reported the presence of ST1 and S1137 in SCCmec type IV strains and ST5 in SCCmec type V strain. Interesting findings were that ST1-SCCmec IV has been reported by Otter and French in a study done on drug users and the homeless in South London [34] and ST5-SCCmec V was found in Japanese CA-MRSA isolates [35] which may indicate the invasion of these clones into Malaysia. The occurrence of the international major clones ST239-SCCmec III and ST22SCCmec IV in Malaysia as well in other countries exhibited the epidemic nature of these clones [13]. To date, there is no study reporting ST1137-SCCmec type IV strains.

The untypeable SCCmec strains with ST239 and ST508 were not assigned to any clusters and appeared as singleton by PFGE. The untypeable CA-MRSA strain with novel ST508 might have derived from ST45 as it appeared to be a single locus (SLV) variant of ST45. According to Berglund et al. [36], MRSA strains that could not be typed by SCCmec typing might cause by some genetic rearrangement or mutations. This led to the emergence of a new highly pathogenic CA-MRSA clone which could have spread to the hospital. ST45 was previously reported as an epidemic strains in Germany and the Netherlands [37] and was present in MRSA bacteraemia isolates in a study done in Switzerland [38].

PFGE was shown to be more discriminatory than MLST in subtyping the MRSA strains. Based on PFGE, the strains had greater diversity with Simpson's index of diversity, D of 0.946 (C.I.N.A. 0.916-0.976), on the other hand, for MLST, the strains were less diverse with Simpson's index of diversity, D of 0.508 (C.I.N.A. 0.4030.613). The majority of MRSA strains in this 2-year study period belonged to the pandemic clone SCCmec III-ST239 and most of them had pulsotype C. The predominance of this pulsotype could be due to the increase in nosocomial transmission within this hospital. In addition, the presence of this clone indicates the persistence of this clone and was identified as an endemic strain in this hospital [39].

\section{Limitations}

The limitations for this study is the clinical data for some 2011 and 2012 MRSA strains could not be retrieved, and hence a comprehensive correlation between phenotypic, molecular and clinical data cannot be made.

\section{Conclusions}

MRSA strains belonging to SCCmec type III were predominant in this hospital over the 2-year study period and the prevalence of PVL gene among 2011 MRSA strains were $5.3 \%$ with none detected in 2012 MRSA strains. The characteristics of MRSA strains that caused bacteraemia were genetically diverse by the presence of different clones circulating in this hospital, in which the majority belonged to SCCmec type III with MLST ST239 and exhibited pulsotype C. However, the presence of SCCmec type IV with MLST ST22 which is usually community-acquired is gaining prominence as they have become nosocomial pathogens and may replace the predominant SCCmec type III strains in this hospital. There were also emergence of novel clones which require further studies and proper monitoring as these clones may have epidemic and pathogenic potentials that could pose serious threat to public health.

\section{Abbreviations \\ CA: Community-acquired; CC: Clonal complex; CDC: Centers for Disease Control and Prevention; CLB: cell lysis buffer; CLSI: Clinical and Laboratory Standards Institute; CSB: Cell suspension buffer; CSF: Cerebrospinal fluid; FOX: Cefoxitin disk; HA: Hospital-acquired; MDROs: Multidrug resistant Organisms; MIC: Minimum inhibitory concentration; MLST: Multilocus sequence typing; MRSA: Methicillin-resistant Staphylococcus aureus; PCR: Polymerase chain reaction; PFGE: Pulsed-field gel electrophoresis; PVL: Panton-Valentine leukocidin; SCCmec: staphylococcal cassette chromosome mec; SSTIs: Skin and soft tissue infections; ST: Sequence type; TE: Tris-EDTA; TSA: Tryptic Soy Agar; UMMC: University Malaya Medical Centre; UPGMA: Unweighted pair group method with arithmetic averages}

\section{Acknowledgements}

This research was funded by FRGS, MOE (FP016-2014B) and PPP grant (PG174-2015B) from Universiti Malaya.

\section{Funding}

Not applicable.

Availability of data and materials

All data generated or analyzed during this study are included in this published article. De-identified raw data will be made available upon reasonable request addressed to the corresponding author. 


\section{Authors' contributions}

PSS carried out the experiments, clinical data collection, data analysis and interpretation and drafted the manuscript. CSJT participated in study design, supervised the project, data interpretation and drafted the manuscript. NI and HS participated in the selection of strains, providing the strains, helped in the interpretation of antimicrobial susceptibility data and editing of the manuscript. AK, ICS and SFSO participated in the study design. KLT provided control strains for SCCmec typing, equipment for PFGE and helped in drafting the manuscript. SP participated in the study design, coordinated and supervised the project and co-wrote the manuscript. All authors read and approved the final manuscript.

\section{Competing interests}

The authors declare that they have no competing interests.

\section{Consent for publication}

Not applicable.

\section{Ethics approval and consent to participate}

This study was approved by Medical Ethics Committee of University Malaya Medical Centre (UMMC) on 7th June 2014 (MEC ID: 20145-168). This was a retrospective study and only bacterial strains were collected. No patient was directly involved, hence obtaining individual patient consent was not required.

\section{Publisher's Note}

Springer Nature remains neutral with regard to jurisdictional claims in published maps and institutional affiliations.

\section{Author details}

'Department of Medical Microbiology, Faculty of Medicine, University of Malaya, 50603 Kuala Lumpur, Malaysia. ${ }^{2}$ Department of Medicine, Faculty of Medicine, University of Malaya, 50603 Kuala Lumpur, Malaysia. Institute of Biological Sciences, Faculty of Science, University of Malaya, 50603 Kuala Lumpur, Malaysia.

Received: 29 November 2016 Accepted: 5 April 2017 Published online: 13 April 2017

\section{References}

1. Stefani S, Chung DR, Lindsay JA, Friedrich AW, Kearns AM, Westh $H$, Mackenzie FM. Meticillin-resistant Staphylococcus aureus (MRSA): global epidemiology and harmonisation of typing methods. Int J Antimicrob Agents. 2012;39(4):273-82. doi:10.1016/j.jjantimicag.2011.09.030.

2. Rohani MY, Raudzah A, Lau MG, Zaidatul AA, Salbiah MN, Keah KC, Noraini A, Zainuldin T. Susceptibility pattern of Staphylococcus aureus isolated in Malaysian hospitals. Int J Antimicrob Agents. 2000;13(3): 209-13. doi:10.1016/50924-8579(99)00129-6.

3. Ahmad N, Ruzan IN, Abd Ghani MK, Hussin A, Nawi S, Aziz MN, Maning N, Eow VL. Characteristics of community- and hospital- acquired meticillinresistant Staphylococcus aureus strains carrying SCCmec type IV isolated in Malaysia. J Med Microbiol. 2009;58(9):1213-8. doi:10.1099/jmm.0.011353-0.

4. Rodriguez-Noriega $E$, Seas C. The changing pattern of methicillin-resistant Staphylococcus aureus clones in Latin America: implications for clinical practice in the region. Braz J Infect Dis. 2010;14(Suppl 2):87-96. doi:10.1590/ S1413-86702010000800004

5. Matouskova I, Janout V. Current knowledge of Methicillin-resistant Staphylococcus aureus and community-associated Methicillin-resistant Staphylococcus aureus. Biomed Pap Med Fac Univ Palacky Olomouc Czech Repub. 2008;152(2):191-202. doi:10.5507/bp.2008.030.

6. Ito T, Hiramatsu K, Oliveira DC, et al. International Working Group on the Staphylococcal Cassette Chromosome elements. n.d. Available from: http:// www.sccmec.org/Pages/SCC_TypesEN.html. Accessed 5 Sep 2016.

7. Ghaznavi-Rad E, Nor Shamsudin M, Sekawi Z, van Belkum A, Neela V. A simplified multiplex PCR assay for fast and easy discrimination of globally distributed staphylococcal cassette chromosome mec types in methicillinresistant Staphylococcus aureus. J Med Microbiol. 2010;59:1135-9. doi:10. 1099/jmm.0.021956-0.

8. Szabo J. Molecular methods in epidemiology of Methicillin resistant Staphylococcus aureus (MRSA): advantages, disadvantages of different techniques. J Med Microb Diagn. 2014;3(3):1-3. doi:10.4172/2161-0703.1000147.
9. Deurenberg RH, Kalenic S, Friedrich AW, Van Tiel FH, Stobberingh EE. Molecular epidemiology of methicillin-resistant Staphylococcus aureus. Commun Curr Res Educ Top Trends Appl Microbiol. 2007:766-77. Available from: http://www.formatex.org/microbio/pdf/pages766-777.pdf Accessed 10 Sep 2016

10. Dhawan B, Rao C, Udo EE, Gadepalli R, Vishnubhatla S, Kapil A. Dissemination of methicillin-resistant Staphylococcus aureus SCCmec type IV and SCCmec type $\checkmark$ epidemic clones in a tertiary hospital: challenge to infection control. Epidemiol Infect. 2015;143(2):343-53. doi:10.1017/s095026881400065x.

11. Lim KT, Hanifah YA, Mohd Yusof MY, Ito T, Thong KL. Comparison of methicillin-resistant Staphylococcus aureus strains isolated in 2003 and 2008 with an emergence of multidrug resistant ST22: SCCmec IV clone in a tertiary hospital, Malaysia. J Microbiol Immunol Infect. 2013;46(3):224-33. doi:10.1016/j.jmii.2013.02.001.

12. Lim KT, Yeo CC, Suhaili Z, Thong KL. Comparison of Methicillin-resistant and Methicillin-sensitive Staphylococcus aureus strains isolated from a tertiary Hospital in Terengganu, Malaysia. Jpn J Infect Dis. 2012;65(6):502-9. doi:10. 7883/yoken.65.502.

13. Ghaznavi-Rad E, Nor Shamsudin M, Sekawi Z, Khoon LY, Aziz MN, Hamat RA, et al. Predominance and emergence of clones of hospital-acquired Methicillin-resistant Staphylococcus aureus in Malaysia. J Clin Microbiol. 2010; 48(3):867-72. doi:10.1128/jcm.01112-09.

14. Gopal Katherason S, Naing L, Jaalam K, Kamarul Imran Musa K, Nik Abdullah NM, Aiyar S, et al. Prospective surveillance of nosocomial device-associated bacteremia in three adult intensive units in Malaysia. Trop Biomed. 2010;27(2):308-16.

15. Ahmad N, Nawi S, Rajasekaran G, Maning N, Aziz MN, Husin A, Rahman NIA. Increased vancomycin minimum inhibitory concentration among Staphylococcus aureus isolates in Malaysia. J Med Microbiol. 2010;59(12): 1530-2. doi:10.1099/jmm.0.022079-0.

16. Coombs GW, Pearson JC, O'Brien FG, Murray RJ, Grubb WB, Christiansen KJ. Methicillin-resistant Staphylococcus aureus clones. Western Australia Emerg Infect Dis. 2006;12(2):241. doi:10.3201/eid1202.050454.

17. Coombs GW, Nimmo GR, Pearson JC, Christiansen KJ, Bell JM, Collignon PJ, McLaws ML, et al. Prevalence of MRSA strains among Staphylococcus aureus isolated from outpatients, 2006. Commun Dis Intell Q Rep. 2009;33(1):10-20.

18. David MZ, Daum RS. Community-associated Methicillin-resistant Staphylococcus aureus: epidemiology and clinical consequences of an emerging epidemic. Clin Microbiol Reviews. 2010;23(3):616-87. doi:10.1128/ CMR.00081-09.

19. Chen CJ, Huang YC. New epidemiology of Staphylococcus aureus infection in Asia. Clin Microbiol Infect. 2014;20(7):605-23. doi:10.1111/ 1469-0691.12705.

20. Milheirico C, Oliveira DC, de Lencastre H. Update to the multiplex PCR strategy for assignment of mec element types in Staphylococcus aureus. Antimicrob Agents Chemother. 2007;51(9):3374-7. doi:10.1128/aac.00275-07.

21. Milheirico C, Oliveira DC, de Lencastre H. Multiplex PCR strategy for subtyping the staphylococcal cassette chromosome mec type IV in methicillin-resistant Staphylococcus aureus: SCCmec IV multiplex. I Antimicrob Chemother. 2007; 60(1):42-8. doi:10.1093/jac/dkm112.

22. Zhang K, McClure JA, Elsayed S, Louie T, Conly JM. Novel multiplex PCR assay for characterization and concomitant Subtyping of staphylococcal cassette chromosome mec types I to V in Methicillin-resistant Staphylococcus aureus. J Clin Microbiol. 2005;43(10):5026-33. doi:10.1128/jcm.43.10.5026-5033.2005.

23. Holmes A, Ganner M, McGuane S, Pitt TL, Cookson BD, Kearns AM. Staphylococcus aureus Isolates carrying Panton-Valentine Leucocidin genes in England and Wales: frequency, characterization, and association with clinical disease. J Clin Microbiol. 2005;43(5):2384-90. doi:10.1128/JCM.43.5. 2384-2390.2005

24. Enright MC, Day NP, Davies CE, Peacock SJ, Spratt BG. Multilocus sequence typing for characterization of Methicillin-resistant and Methicillin-susceptible clones of Staphylococcus aureus. J Clin Microbiol. 2000;38(3):1008-15.

25. Centers for Disease Control and Prevention. Oxacillin-resistant Staphylococcus aureus on PulseNet (OPN): Laboratory Protocol for Molecular Typing of S. aureus by Pulsed-field Gel Electrophoresis (PFGE). n.d. Available from: http://www.cdc.gov/mrsa/pdf/ar_mras_PFGE_s_aureus.pdf. Accessed 5 Sep 2016.

26. File TM. Methicillin-resistant Staphylococcus aureus (MRSA): focus on community-associated MRSA. South Afr J Epidemiol Infect. 2008;23(2):13-5. doi:10.1080/10158782.2008.11441307. 
27. Shitrit P, Openhaim M, Reisfeld S, Paitan Y, Regev-Yochay G, Carmeli Y, Chowers M. Characteristics of SCCmec IV and V Methicillin-resistant Staphylococcus aureus (MRSA) in Israel. Isr Med Assoc J. 2015;17(8):470-5.

28. Chen BJ, Huang SY, Pan KY, Dai XL, Li CW, Liu XQ, et al. Molecular characterization of community-acquired methicillin-resistant Staphylococcus aureus isolated from patients with skin and soft tissue infection in a teaching hospital. Int J Clin Exp Med. 2016;9(1):235-43.

29. Song JH, Hsueh PR, Chung DR, Ko KS, Kang Cl, Peck KR, et al. Spread of methicillin-resistant Staphylococcus aureus between the community and the hospitals in Asian countries: an ANSORP study. J Antimicrob Chemother. 2011;66(5):1061-9. doi:10.1093/jac/dkr024

30. Holmes NE, Johnson PD, Howden BP. Relationship between Vancomycin-resistant Staphylococcus aureus, Vancomycin-Intermediate $S$. aureus, high Vancomycin MIC, and outcome in Serious S. aureus infections. J Clin Microbiol. 2012:50(8):2548-52. doi:10.1128/JCM.00775-12.

31. Boye K, Bartels MD, Andersen IS, Moller JA, Westh H. A new multiplex PCR for easy screening of methicillin-resistant Staphylococcus aureus SCCmec types I-V. Clin Microbiol Infect. 2007;13(7):725-7. doi:10.1111/j. 1469-0691.2007.01720.x.

32. Trindade PDA, Pacheco RL, Costa SF, Rossi F, Barone AA, Mamizuka EM, Levin AS. Prevalence of SCCmec type IV in Nosocomial bloodstream isolates of Methicillin-resistant Staphylococcus aureus. J Clin Microbiol. 2005;43(7): 3435-7. doi:10.1128/JCM.43.7.3435-3437.2005.

33. Sam IC, Kahar-Bador M, Chan YF, Loong SK, Mohd Nor Ghazali F. Multisensitive community-acquired methicillin-resistant Staphylococcus aureus infections in Malaysia. Diagn Microbiol Infect Dis. 2008;62(4):437-9. doi:10.1016/.diagmicrobio. 2008.07.016.

34. Neela V, Mohd Zafrul A, Mariana NS, van Belkum A, Liew YK, Rad EG. Prevalence of ST9 Methicillin-resistant Staphylococcus aureus among pigs and pig handlers in Malaysia. J Clin Microbiol. 2009;47(12):4138-40. doi:10. 1128/JCM.01363-09

35. Urushibara N, Kawaguchiya M, Kobayashi N. Two novel arginine catabolic mobile elements and staphylococcal chromosome cassette mec composite islands in community-acquired methicillin-resistant Staphylococcus aureus genotypes ST5-MRSA-V and ST5-MRSA-II. J Antimicrob Chemother. 2012 67(8):1828-34. doi:10.1093/jac/dks157.

36. Berglund C, Molling P, Sjoberg L, Soderquist B. Predominance of staphylococcal cassette chromosome mec (SCCmec) type IV among methicillin-resistant Staphylococcus aureus (MRSA) in a Swedish county and presence of unknown SCCmec types with Panton-Valentine leukocidin genes. Clin Microbiol Infect. 2005;11(6):447-56. doi:10.1111/j.1469-0691.2005.01150.x.

37. Moore CL, Osaki-Kiyan P, Perri M, Donabedian S, Haque NZ, Chen A, Zervos MJ. USA600 (ST45) methicillin-resistant Staphylococcus aureus bloodstream infections in urban Detroit. J Clin Microbiol. 2010;48(6): 2307-10. doi:10.1128/jcm.00409-10.

38. Hernandez D, Seidl K, Corvaglia AR, Bayer AS, Xiong YQ, Francois P. Genome sequences of sequence type 45 (ST45) persistent Methicillin-resistant Staphylococcus aureus (MRSA) Bacteremia strain 300-169 and ST45 resolving MRSA Bacteremia strain 301-188. Genome Announc. 2014;2(2):1-2. doi:10. 1128/genomeA.00174-14.

39. Norazah A, Liew SM, Kamel AG, Koh YT, Lim VK. DNA fingerprinting of Methicillin-resistant Staphylococcus aureus by pulsed-field gel electrophoresis (PFGE): Comparison of strains from 2 Malaysia hospitals. Singap Med J. 2001:42(1):15-9.

\section{Submit your next manuscript to BioMed Central and we will help you at every step:}

- We accept pre-submission inquiries

- Our selector tool helps you to find the most relevant journal

- We provide round the clock customer support

- Convenient online submission

- Thorough peer review

- Inclusion in PubMed and all major indexing services

- Maximum visibility for your research

Submit your manuscript at www.biomedcentral.com/submit 